\title{
Design and Modeling of a Semi Circular-Shaped Double Band-Notched UWB Antenna
}

\author{
Khalil H. Sayidmarie ${ }^{1}$, and Likaa S. Yahya ${ }^{2}$ \\ \{kh.Sayidmarie@uoninevah.edu.iq ${ }^{1}$, likaas.yahya@gmail.com² ${ }^{2}$, \\ College of Electronics Eng., Ninevah University, $\operatorname{Iraq}^{1}$, \\ Dept. of Electronic Techniques, Northern Technical University, Mosul, Iraq ${ }^{2}$
}

\begin{abstract}
An UWB semi-circular-shaped monopole antenna with double band-notching is presented. The suggested antenna is designed to have two notched-bands to avoid the undesirable interferences with the $3.5 \mathrm{GHz}$ band for WiMAX system and the $5.5 \mathrm{GHz}$ band for WLAN system with a simple structure. The first notch is realized by etching an arc slot in the arc patch. Whereas the other notch is achieved by adding a T-shaped stub on the feeding line. The suggested antenna has a small size of $30 \times 25 \mathrm{~mm} 2$. The proposed antenna achieves UWB conditions. It operates within a wide band from 2.7 to above $18 \mathrm{GHz}$ with two rejected bands at $3.5 \mathrm{GHz}$ and $5.5 \mathrm{GHz}$. The performance of the suggested dual bandnotched UWB antenna has been investigated using the CST Software Package. An equivalent circuit of the proposed antenna was realized and investigated. The lumped elements employed in the equivalent circuit modeling of the suggested monopole antenna were determined using the Advanced Design System (ADS) software.
\end{abstract}

Keywords: UWB antenna; band-notching; antenna modeling; monopole antenna, Slot, ADS.

\section{Introduction}

UWB antennas share parts of their spectrum with the high-power and narrow-band WiMAX working in the frequency band of $3.3-3.8 \mathrm{GHz}$, as well as the WLAN operating at the 5.15$5.825 \mathrm{GHz}$ band. These narrow-band systems can produce severe interferences with the UWB system leading to degradation of performance. So, it is required to design UWB antennas that are able to notch the above bands to avoid electromagnetic interferences with the UWB systems [1]. Different techniques have been employed for the design of UWB antennas to obtain single, double, and triple band-notching functions [2-13]. The notching at a certain frequency was achieved by inserting a slot in the shape of the letter $U$ [2-5]. A slot and a metallic ring were combined as in [4], while in [6], a slot having a V-shape was used. In [7], a triple-band notching was achieved by etching an inverted $\mathrm{U}$-slot and a $\mathrm{C}$-shaped slot on the radiating patch, while another U-shaped slot was used in the microstrip feed line. In another design, the triple band was achieved by etching two rotated T-shaped slits in the square radiating patch as well as incorporating an inverted $\Omega$-shaped and two rectangular slots in the ground plane [8]. In [9], the three notched bands were achieved an E-shaped resonator, meandered slot, and U-shaped slot were used. The three bands can be independently chosen in the design stage. The three notched bands in [10] were more elaborately obtained where the first two bands were achieved by etching two inverted $\mathrm{T}$-shaped slots at the lower edge of the radiating patch, and by cutting a 
comb-shaped slot at the upper side of the radiating patch. The third band was obtained by cutting two rectangular slots and a C-shaped slot, and adding two small parasitic patches at the center of the radiating element. A C-shaped narrow strip was connected at one of its ends to the elliptical radiating patch to achieve the band notch [11]. An open-ended $\lambda \mathrm{g} / 4$ hook-shaped slot was used in [12] to obtain a single band-notched characteristic. Defected ground compact electromagnetic bandgap (DG-CEBG) designs were used to accomplish notches in WiMAX and WLAN bands [13]. A pair of parasitic resonators were placed beneath the radiating patch to accomplish two notched bands [14]. Another design to achieve two notched bands was to use four circular patchloaded stubs on the radiating element, and two complementary split rings etched on the ground plane [15]. Two split ring slots etched on the radiating patch were used to achieve two notched bands [16].

This paper presents a compact semi-circular-shaped monopole antenna with dual rejected-bands at 3.5 and $5.5 \mathrm{GHz}$. An arc slot is cut on the radiating patch to create the desired notched band at $5.5 \mathrm{GHz}$, while a T-shaped stub is added to the feed line to create the second notched band at 3.5GHz. The proposed antenna achieved UWB operation with two notched bands covering the ranges of 2.9-4.1 GHz and 4.8-6.1GHz. Modeling of the UWB antenna with the band-notching is investigated using the ADS software.

\section{Design of Proposed Double Band- Notched UWB Antenna.}

A planar monopole antenna of semi-circular shape that was developed for UWB applications [17] is considered in the investigations. Figure 1 illustrates the distributions of the surface current of the UWB antenna (reference antenna) at 3.5 and $5.5 \mathrm{GHz}$ frequencies. The current density is focused along the feed line and the lower parts of the radiator. These locations have been taken into consideration when designing the band -notched structures. The double notched-bands are realized by an arc-slot in the radiating patch and including a T-stub to the feed line of reference antenna, as shown in Fig. 2. The dimensions of the slot and stub are chosen to achieve two notched- bands at 5.5 and $3.5 \mathrm{GHz}$. The total length of the arc slot $\mathrm{L}_{\text {slot }}$ at notched frequency $5.5 \mathrm{GHz}$ is calculated by assuming $\mathrm{L}_{\text {slot }}=1 / 2$ effective wavelength at notched frequency:

$$
L_{\text {slot }}=\frac{c}{\left(2 f \sqrt{\frac{\left(\varepsilon_{r}+1\right)}{2}}\right)}
$$

Where $\mathrm{c}$ is the speed of the light, $\mathrm{f}$ is the resonant frequency of the arc slot, and $\varepsilon_{\mathrm{r}}$ is the relative permittivity of the substrate. The arc-length slot is evaluated to be $16.75 \mathrm{~mm}$ for $5.5 \mathrm{GHz}$ notch. The physical length of the T-shaped open stub $\mathrm{L}_{\text {stub }}$ at a notched frequency of $3.5 \mathrm{GHz}$ is calculated by

$$
L_{s t u b} \cong T_{1}+\frac{T_{2}}{2}=\frac{c}{4 f \sqrt{\varepsilon_{e}}}
$$

Where $\mathrm{f}$ denotes the frequency of the notch and $\varepsilon_{\mathrm{e}}$ denotes the effective dielectric constant, which can be calculated as [18].

$$
\epsilon_{e}=\frac{\left(\epsilon_{r}+1\right)}{2}+\frac{\epsilon_{r}-1}{2}\left(\sqrt{1+\frac{12 h}{W}}\right)^{-1}
$$


The dimensions of both of the T-shaped stub and the arc-shaped slot are adjusted in the simulations to control the center frequencies of the lower and higher notched-band. To improve the matching of the antenna, a defected ground plane of dimensions $\mathrm{w}_{\mathrm{sg}} \times 1_{\mathrm{sg}}$ located at the top of the ground plane is introduced, as shown in Figs. 2. Table 1 shows the values of the parameters of the designed antenna.

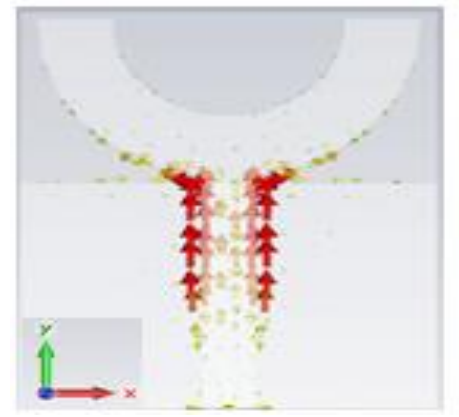

(a)

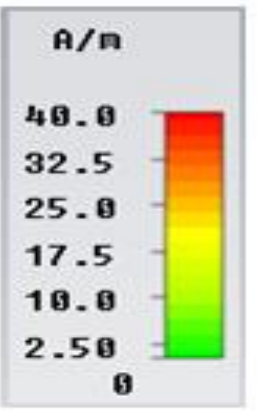

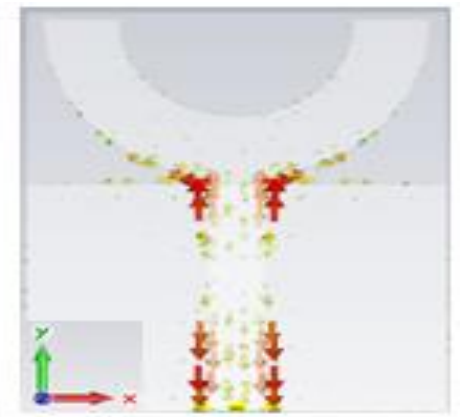

(b)

Fig. 1. The simulated current distributions of UWB antenna (reference antenna) at;

(a) $3.5 \mathrm{GHz},(\mathrm{b}) 5.5 \mathrm{GHz}$.

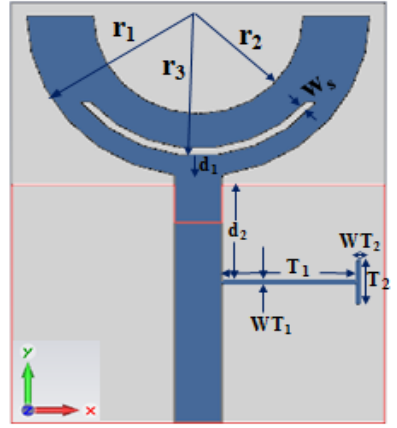

(a)

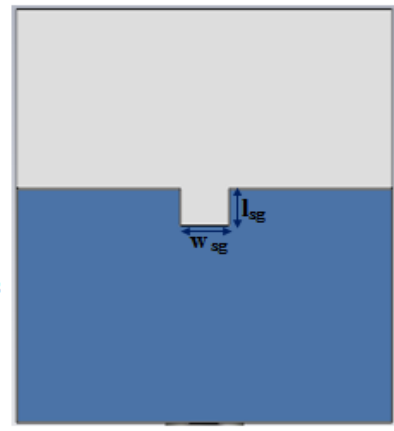

(b)

Fig. 2. The configuration of the proposed antenna with slot and stub for band notching ;

(a) front view, (b) back view.

Table 1. Values of the parameters of the designed antenna.

\begin{tabular}{||c||c|c|c|c|c|c|c|c|c|c|c|c||}
\hline \hline parameter & $\mathrm{r}_{1}$ & $\mathrm{r}_{2}$ & $\mathrm{r}_{3}$ & $\mathrm{~T}_{1}$ & $\mathrm{~T}_{2}$ & $\mathrm{WT}_{1}$ & $\mathrm{WT}_{2}$ & $\mathrm{Ws}$ & $\mathrm{d}_{1}$ & $\mathrm{~d}_{2}$ & $\mathrm{~W}_{\mathrm{sg}}$ & $1_{\mathrm{sg}}$ \\
\hline Value (mm) & 11.5 & 7 & 10 & 9 & 3.1 & 0.2 & 0.2 & 0.5 & 0 & -6.85 & 3.2 & 2.7 \\
\hline \hline
\end{tabular}

\section{Simulation Results}

To optimize the performance of the proposed dual band-notched antenna, five design cases were thoroughly investigated. In each case, one or two of the parameters is tuned, while the other parameters remained fixed as those in (Table-1), to achieve better results. The parameters of the five cases are explained in the following:

Case-1: Same parameters as those shown in Table 1. 
Case-2: The position of the slot is moved down by $0.5 \mathrm{~mm} \quad\left(\mathrm{~d}_{1}\right.$ is changed from 0 to $-0.5 \mathrm{~mm}$ ). Case-3: The width of the stub is increased from $0.2 \mathrm{~mm}$ to $0.3 \mathrm{~mm}$ for the long arm of the stub (WT1), and from $0.2 \mathrm{~mm}$ to $0.5 \mathrm{~mm}$ for the short arm of the stub $\left(\mathrm{WT}_{2}\right), \mathrm{d} 1$ is changed from 0.5 in case two to $-0.75 \mathrm{~mm}$ in this case while the other parameters of case- 2 are kept constant. Case-4: The position of the T-stub in case- 3 was moved down by $3 \mathrm{~mm}\left(\mathrm{~d}_{2}\right.$ is changed from $6.85 \mathrm{~mm}$ to $-9.85 \mathrm{~mm}$ ) while the other parameters were kept constant.

Case-5: The position of the T-stub in case- 4 was changed to $-7.7 \mathrm{~mm}$ while the other parameters were kept constant.

The achieved results are shown in Fig.3, and the characteristics of the five achieved responses are compared in Table 2.

In case two, when the position of the slot is moved down by $0.5 \mathrm{~mm}$, it can be seen from Fig. 3 that both the VSWR and the bandwidth of the second notched-frequency increased as compared with case-1. The VSWR increased from 6.44 to 7.67 while the bandwidth of the second notchedfrequency increased from $1.08 \mathrm{GHz}$ to $1.24 \mathrm{GHz}$.

In case-3, the width of the stub is increased from $0.2 \mathrm{~mm}$ to $0.3 \mathrm{~mm}$ for the long arm of the $\operatorname{stub}\left(\mathrm{WT}_{1}\right)$ and from $0.2 \mathrm{~mm}$ to $0.5 \mathrm{~mm}$ for the short arm of the $\mathrm{stub}\left(\mathrm{WT}_{2}\right), \mathrm{d} 1$ is changed from 0.5 in case two to -0.75 in this case while the other parameters in case- 2 are kept constant. Figure $3 \mathrm{~b}$ shows that the VSWR of the first notched-band increased from 25.24 to 33.7 , and the bandwidth of the first notched-band slightly decreased from $1.27 \mathrm{GHz}$ to $1.22 \mathrm{GHz}(3.9 \%)$.

In case- 4 , the position of the T-stub $\left(\mathrm{d}_{2}\right)$ in case- 3 was moved down by $3 \mathrm{~mm}\left(\mathrm{~d}_{2}\right.$ is changed from $-6.85 \mathrm{~mm}$ to $-9.85 \mathrm{~mm}$ ) while the values of the other parameters were kept constant. Figure 3 shows that the VSWR of the first notched-band is almost doubled (increased from 33.74 to 77.4) compared to that of case-3, while the VSWR of the second notched- band increased slightly from 8.6 to 9.5 . The reflection coefficient near $10.4 \mathrm{GHz}$ becomes higher than the $-10 \mathrm{~dB}$ level. In case-5, the position of the T-stub was changed to $-8.35 \mathrm{~mm}$, while the other parameters in case- 4 were kept constant. Figure 3 shows that the VSWR of the first band decreased from 77.4 in case- 4 to 50.2, but there is a good matching over the entire UWB bandwidth. The antenna in case- 5 has been taken an example in the next analysis to find the antenna characteristics and equivalent circuit because it gives good VSWR in both notched bands and good impedance matching over the UWB.

Figure 4 shows the results obtained when using the following substrates; Arlon AR450 $\left(\in_{\mathrm{r}}=\right.$ 4.5, $\tan \delta=0.0035), \mathrm{FR} 4\left(\in_{\mathrm{r}}=4.3, \tan \delta=0.025\right)$, Getek ML200D $\left(\in_{\mathrm{r}}=4.3, \tan \delta=0.0107\right)$, Rogers TMM4 $\left(\in_{\mathrm{r}}=4.3, \tan \delta=0.002\right)$. The four substrates have approximately the same permittivity but different values of the loss tangent. As can be seen from Fig.4, applying the material substrate with a low loss tangent can achieve a better performance in the band notching as the VSWR has increased to 108 at the first notched-band and to 48.5 at the second notched-band but with less matching through the UWB. Higher values of the loss tangent result in lower signal rejection.

Table 2. Comparison between the obtained characteristics of the frequency responses of the five cases.

\begin{tabular}{|c||c|c|c||c|c|c||}
\hline \hline case & B. $W_{l}(\mathrm{GHz})$ & $V S W R 1$ & $f r_{1}(\mathrm{GHz})$ & B. $W_{2}(\mathrm{GHz})$ & $V S W R_{2}$ & $f r_{2}(G H z)$ \\
\hline \hline 1 & 1.3 & 25.79 & 3.57 & 1.08 & 6.44 & 5.46 \\
\hline 2 & 1.27 & 25.24 & 3.53 & 1.24 & 7.67 & 5.5 \\
\hline 3 & 1.22 & 33.74 & 3.39 & 1.35 & 8.6 & 5.46 \\
\hline 4 & 1.23 & 77.4 & 3.37 & 1.36 & 9.5 & 5.38 \\
\hline 5 & 1.25 & 50.2 & 3.43 & 1.4 & 9.35 & 5.41 \\
\hline
\end{tabular}




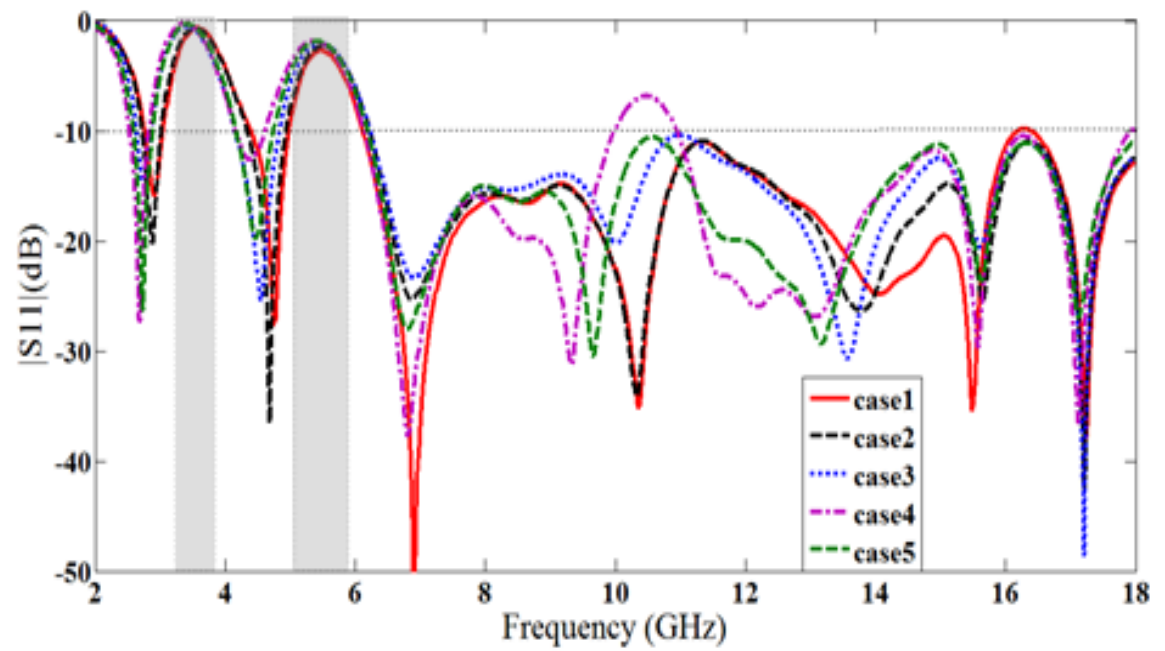

(a)

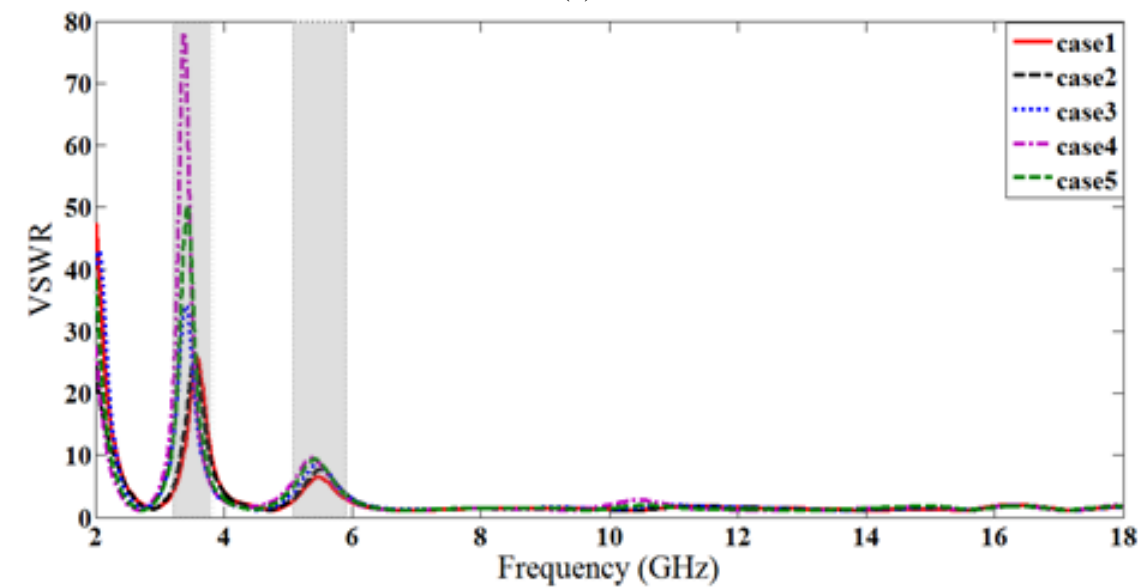

(b)

Fig. 3. The simulated results of the five cases; (a) reflection coefficient $S_{11}$, (b) VSWR

The simulated surface current at 3.5 and $5.5 \mathrm{GHz}$ for the proposed antenna design is presented in Fig. 5a and b, respectively. At $3.5 \mathrm{GHz}$ frequency, the current is focused around the stub, while the arc almost has no current density to radiate from. At $5.5 \mathrm{GHz}$ frequency, the current density is much higher around the slot, where the two parts of the slot have an opposite current, which leads to very little radiation.

The simulated radiation patterns in the H-plane (XZ-plane) and E-plane (YZ-plane) are shown in Fig. 6. It can be observed that the radiation patterns in the XZ-plane are approximately omnidirectional for the three frequencies, while the radiation patterns are bidirectional in the Eplane. As the operating frequency is increased, the $\mathrm{H}$-plane radiation pattern becomes nearer to quasi-omnidirectional, while it remains bidirectional in the E-plane at $8 \mathrm{GHz}$. 


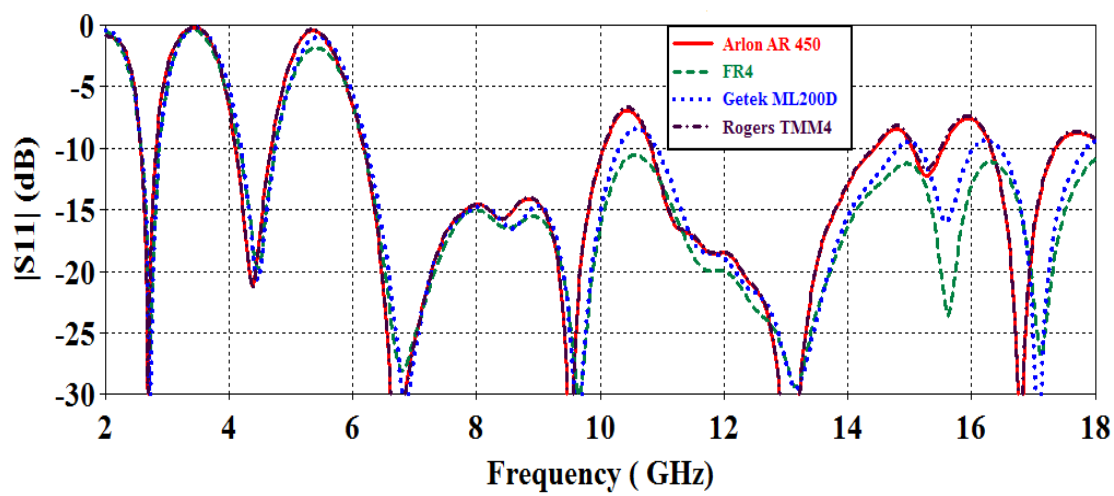

(a)

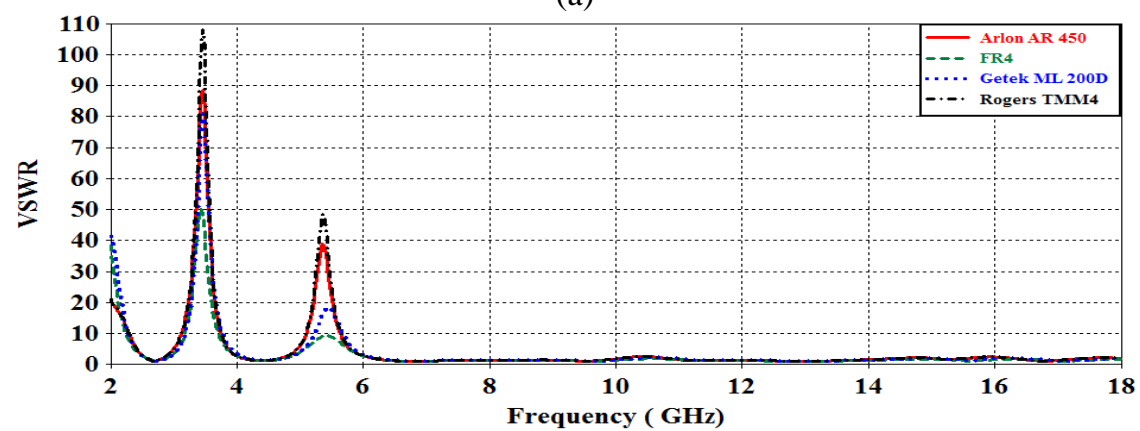

(b)

Fig. 4. The simulated results for case 5 antenna with various substrates;

(a) reflection coefficient $\mathrm{S}_{11}$, (b) VSWR.

Figure 7 shows the gain and total radiation efficiency versus frequency where two sharp dips in both gain and total radiation efficiency occur at the notched frequencies of 3.5 and $5.4 \mathrm{GHz}$. The results mean that the antenna successfully blocks out the signals in the frequencies between 3.2-3.8GHz and 5-5.9GHz. The antenna exhibits good performances at other frequencies in the UWB band. The gain rises slightly with the frequency to a maximum of $4.8 \mathrm{dBi}$ at $16 \mathrm{GHz}$. The maximum efficiency is $84.1 \%$ at $7.39 \mathrm{GHz}$.

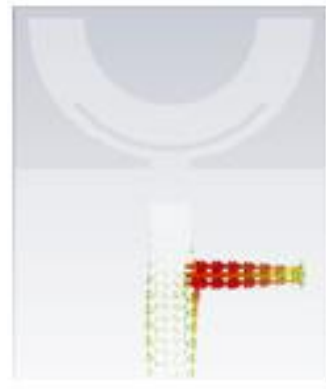

(a)

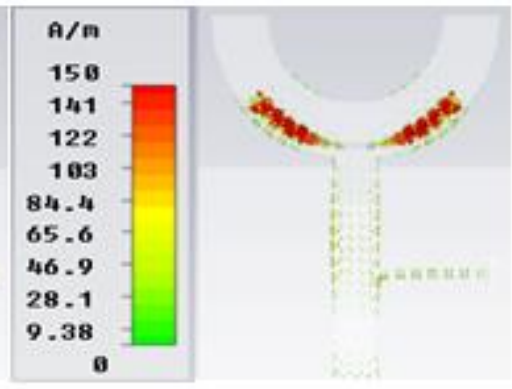

(b)

Fig. 5. The simulated surface current over the antenna geometry at frequency of; (a) $3.5 \mathrm{GHz}$, and (b) $5.5 \mathrm{GHz}$. 

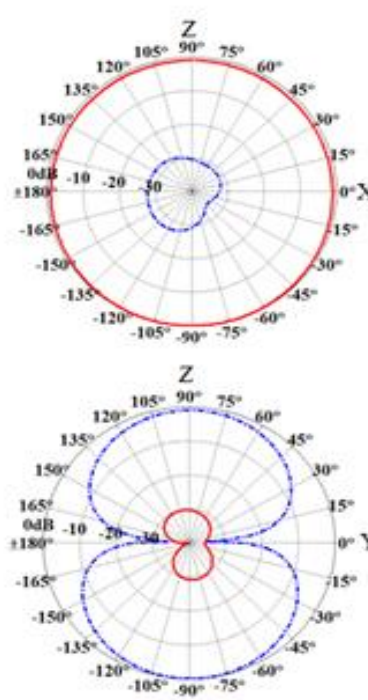

(a)
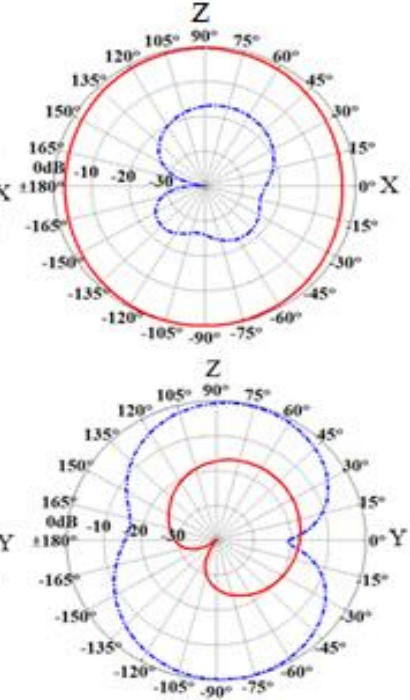

(b)
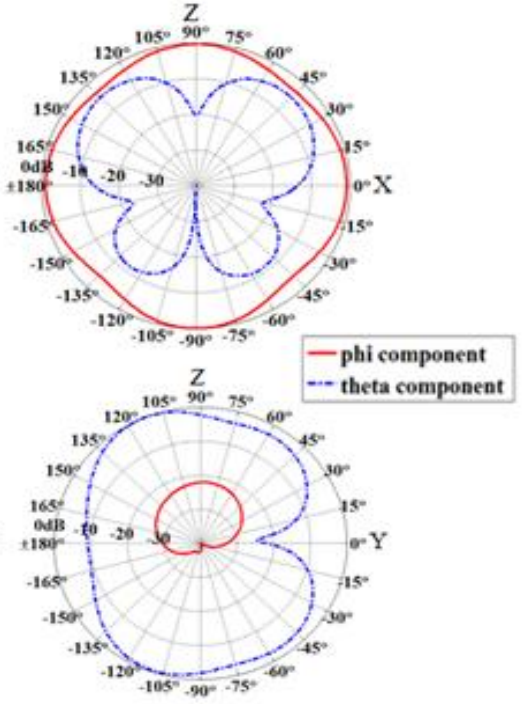

(c)

Fig. 6. The simulated radiation patterns of the proposed antenna at the frequency of; (a) 2.73 , (b) 4.5 , and (c) $8 \mathrm{GHz}$.

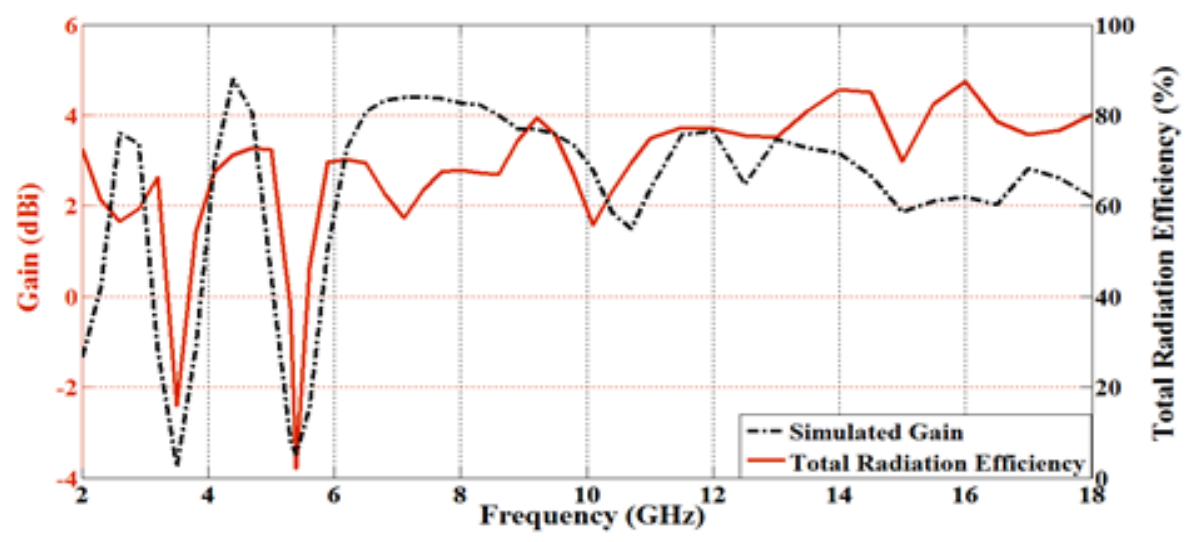

Fig. 7. The frequency response of gain and total radiation efficiency for the proposed antenna.

\section{Equivalent Circuits and Modeling for the Antenna. \\ 4.1 Models derived from the input impedance response.}

The same procedures which were applied in [19] to extract the equivalent circuit element model are used here to derive the equivalent circuit model of the suggested double band-notched UWB antenna. Figure 8 shows the impedance response obtained from the CST-software. Based on the results, anti-resonance of 9 modes can be seen in the investigation band $(2 \mathrm{GHz}-18 \mathrm{GHz})$. At the first notch frequency $(3.5 \mathrm{GHz})$, the resistance has a local maximum, whereas the 
reactance is changing and crossing zero and has a negative derivative. Thus, it is a parallel-type resonance (anti-resonance) with large variation in the values of both the real and imaginary parts. The antenna exhibits open circuit input impedance at the $3.5 \mathrm{GHz}$ notch frequency. At the second notch frequency $(5.5 \mathrm{GHz})$, the input impedance is similar to the impedance of a series RLC circuit, the real part has a local minimum $(6 \Omega)$ while the imaginary part is also crossing zero where its derivative is positive. The antenna exhibits zero input impedance, which leads to the desired impedance mismatch at $5.5 \mathrm{GHz}$ notch frequency. The ADS circuit for the antenna model is given in Fig.9. Table 3 summarizes the values of the elements in the equivalent circuit model for the proposed antenna. The input impedance in the passband is calculated using eight RLC parallel circuits which are connected in series. An additional parallel RLC circuit is added to represent the first band-notched at $3.5 \mathrm{GHz}$, and a shunt RLC-in series resonator is added to represent the second band-notched at $5.5 \mathrm{GHz}$.

Figure 10 shows the variation with the frequency of the input impedance achieved by CST compared to the impedance computed from circuit model. The calculated input impedance has the same trend as the simulated one, although the real and imaginary parts at the first notched frequency are lower than those obtained from the CST simulation.

Figure 11 shows comparisons of the reflection coefficient and VSWR responses of the proposed antenna using CST and the designed circuit model. The figure shows that the model provides good accuracy. The results obtained from the lumped-element equivalent circuit model agree well with those obtained from the CST simulation over the entire UWB frequency range.

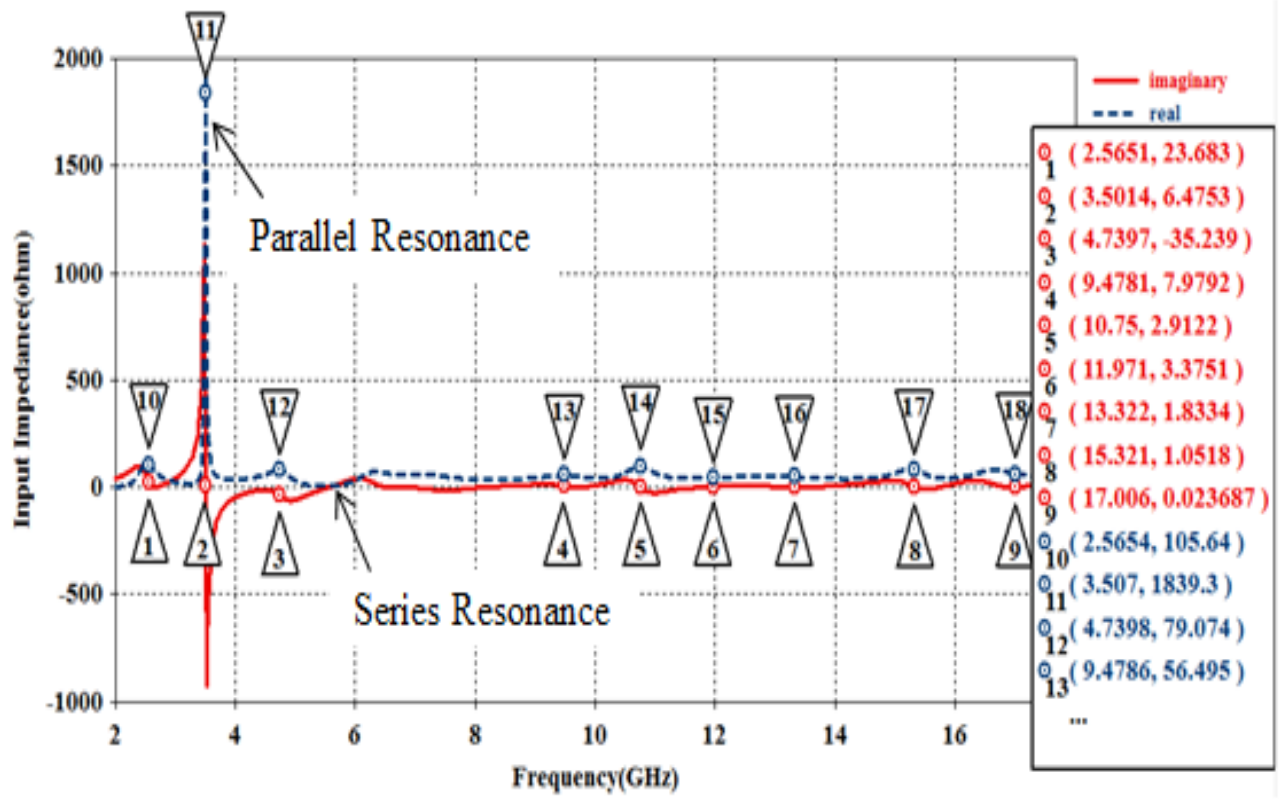

Fig. 8. The frequency response of real and imaginary parts of the input impedance $\left(Z_{\text {in }}\right)$. 


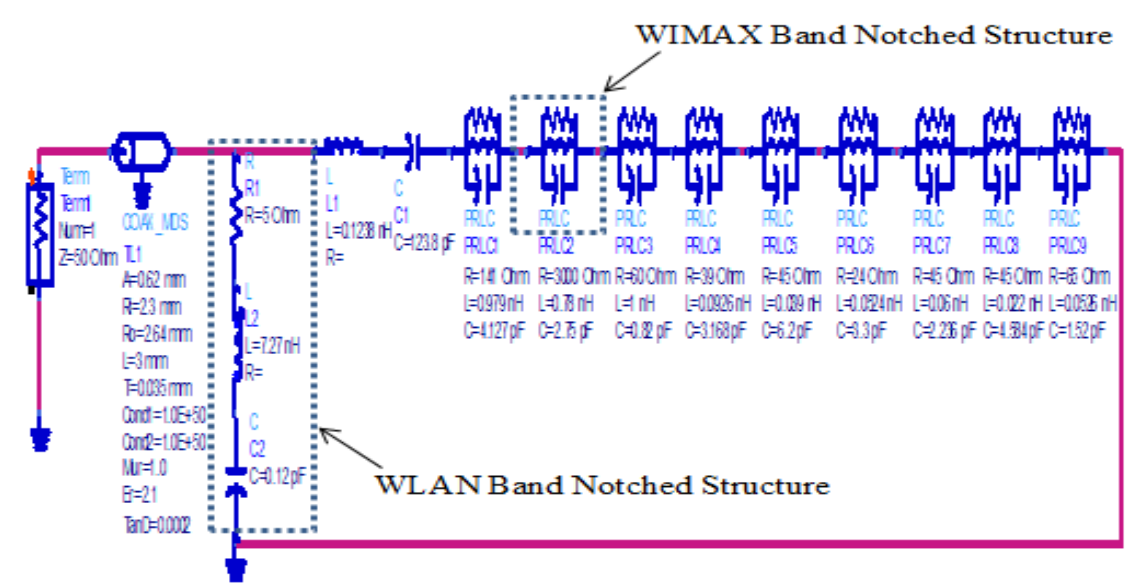

Fig. 9. ADS circuit model for dual-notched antenna.

Table 3. The circuit elements for dual-notched antenna.

\begin{tabular}{|c|c|c|c|c|c|c|c|c|c|c|c|c|}
\hline & $Z_{n}$ & $Z_{0}$ & $Z_{1}$ & $Z_{2}$ & $Z_{3}$ & $Z_{4}$ & $Z_{5}$ & $Z_{6}$ & $Z_{7}$ & $Z_{8}$ & $Z_{9}$ & $Z_{\text {series }}$ \\
\hline \multirow{4}{*}{ 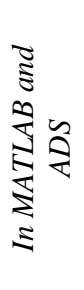 } & $R_{n}(\Omega)$ & & 141 & 3000 & 65 & 39 & 45 & 22 & 45 & 45 & 65 & 5 \\
\hline & $C_{n}(p f)$ & 123.8 & 4.127 & 2.75 & 0.82 & 3.168 & 6.2 & 3.4 & 2.236 & 4.58 & 1.52 & 0.12 \\
\hline & $L_{n}(n H)$ & 0.1233 & 0.979 & 0.78 & 1 & 0.0926 & 0.039 & 0.052 & 0.06 & 0.022 & 0.053 & 7.27 \\
\hline & $f_{n}(G H z)$ & & 2.5 & 3.43 & 5.55 & 9.29 & 10.23 & 11.92 & 13.65 & 15.85 & 17.79 & 5.38 \\
\hline
\end{tabular}

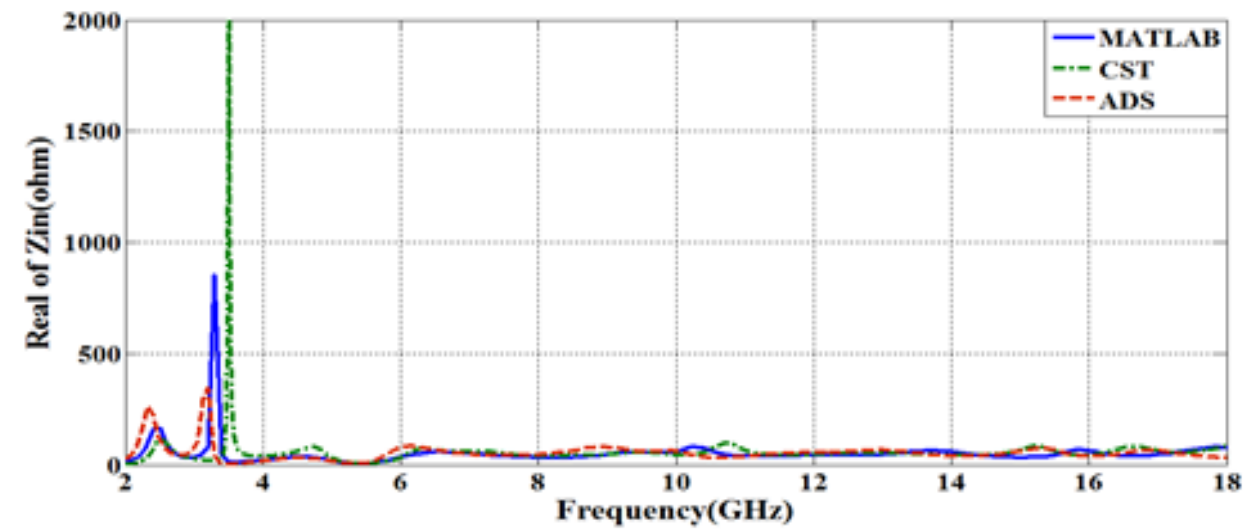

(a) 


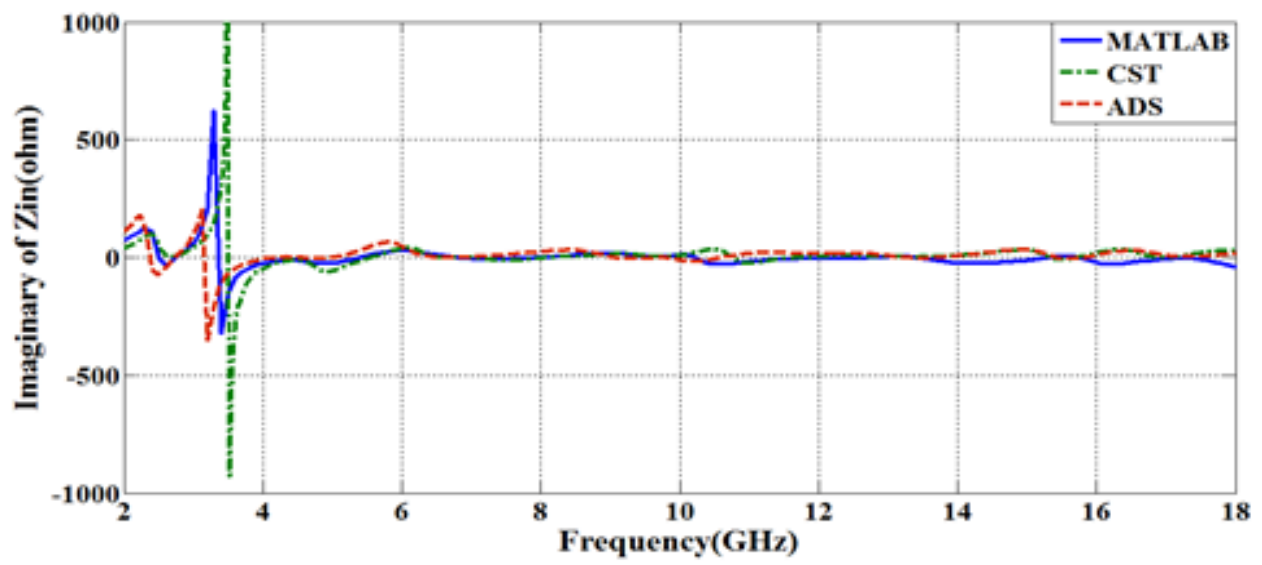

(b)

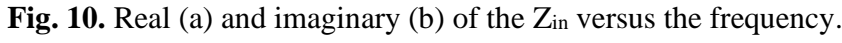

\subsection{The derived models based on transfer function.}

Linearly spaced 26 poles were selected initially, while the adopted number of iterations was (3). Thirteen complex pole pairs were obtained from the fitting procedure. The magnitude rms error was less than $(-35 \mathrm{~dB})$. Table 4 lists the circuit elements achieved for the proposed antenna.

A comparison between the admittance parts of the proposed antenna as determined by CST and from the circuit model as depicted in Fig. 12. Good agreement between simulated results and those obtained from the equivalent circuit modeling is observed. Figure 13 shows comparisons of the reflection coefficient and the VSWR responses of the antenna obtained from the CST against the one achieved from the circuit model. The trends of curves agree well over the UWB band, especially in the double rejected frequency bands. The discrepancy among the curves can be commonly attributed to the inaccuracy in the modeling of the radiating element for the curve fitting.

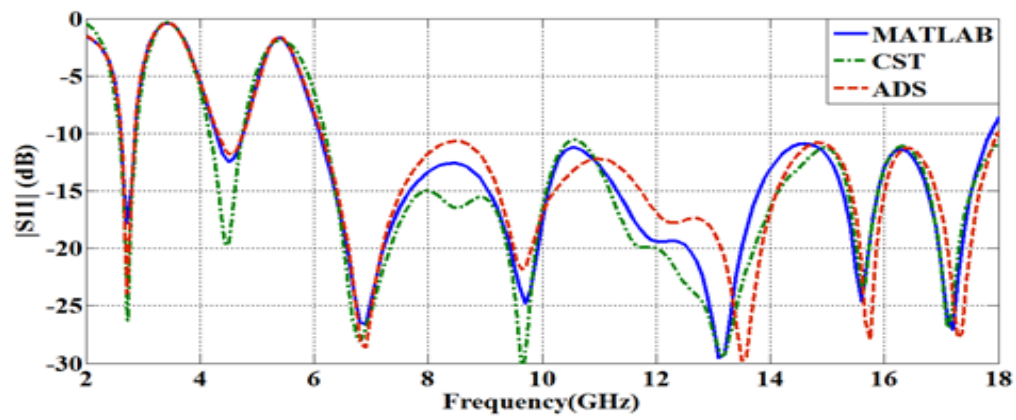

(a) 


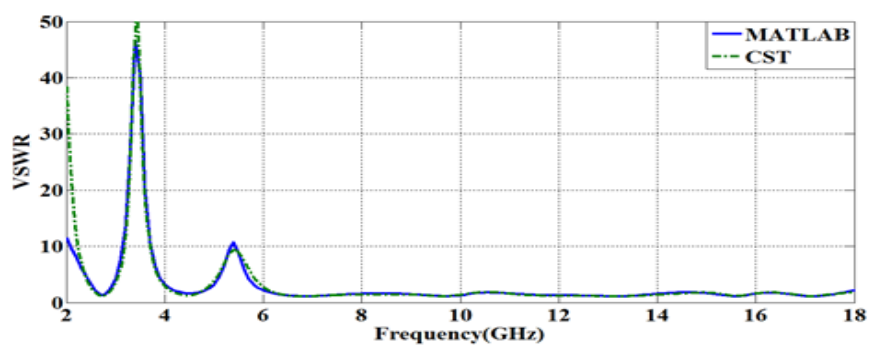

(b)

Fig. 11. Comparison of the $S_{11}$ and the VSWR responses achieved by ADS, CST, and MATLAB.

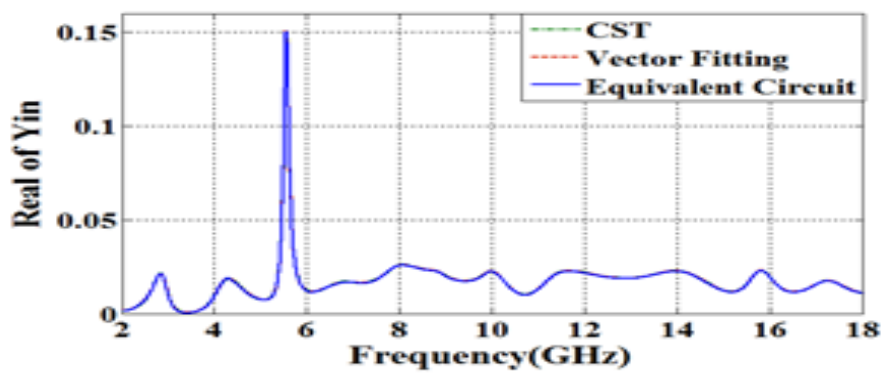

(a)

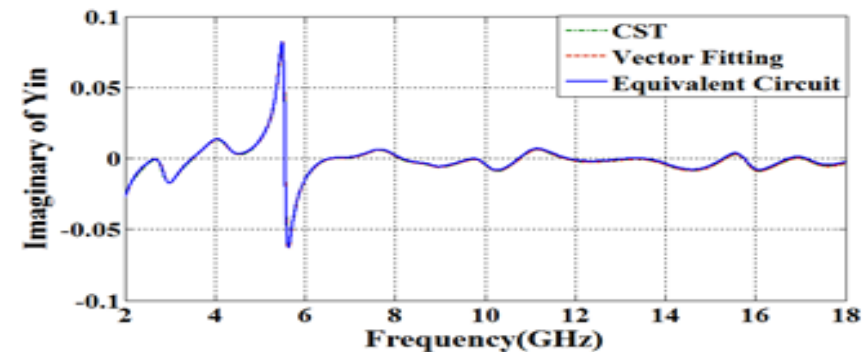

(b)

Fig. 12. Real (a) and imaginary (b) of the admittance parts for three equivalent methodologies.

Table 4. The circuit elements of the proposed antenna.

\begin{tabular}{|c|c|c|c|c|c|c|c|c|c|c|c|c|c||}
\cline { 2 - 12 } \multicolumn{1}{c|}{} & $C_{1}$ & $C_{2}$ & $C_{3}$ & $C_{4}$ & $C_{5}$ & $C_{6}$ & $C_{7}$ & $C_{8}$ & $C_{9}$ & $C_{10}$ & $C_{11}$ & $C_{12}$ & $C_{13}$ \\
\hline \hline$C(p f)$ & 0.007 & -0.11 & 0.01 & 0.029 & -0.0002 & 0.016 & 0.003 & 0.0004 & 0.003 & 0.1 & 0.38 & 0.1 & 0.07 \\
\hline$L(n H)$ & 10.85 & -0.92 & 9.4 & 3.37 & -36.8 & 15.58 & 123 & 47.7 & 19 & 7.76 & 10 & 21.67 & 14.2 \\
\hline$R_{1}(k \Omega)$ & -0.286 & -0.03 & 0.25 & 0.19 & 14.97 & 0.24 & -1.25 & 11.4 & 2.575 & 0.037 & -0.11 & -0.2 & 0.28 \\
\hline$R_{2}(k \Omega)$ & 4 & -3.06 & -4.55 & -0.83 & -15.39 & -5.99 & 30 & -11.9 & -2.83 & -2.48 & 0.2 & 0.8 & -0.93 \\
\hline$R_{0}(\Omega)$ & & & & 52.8 & & & & & & & & & \\
\hline$C_{0}(p f)$ & & & & 0.01 & & & & & & & & & \\
\hline \hline
\end{tabular}




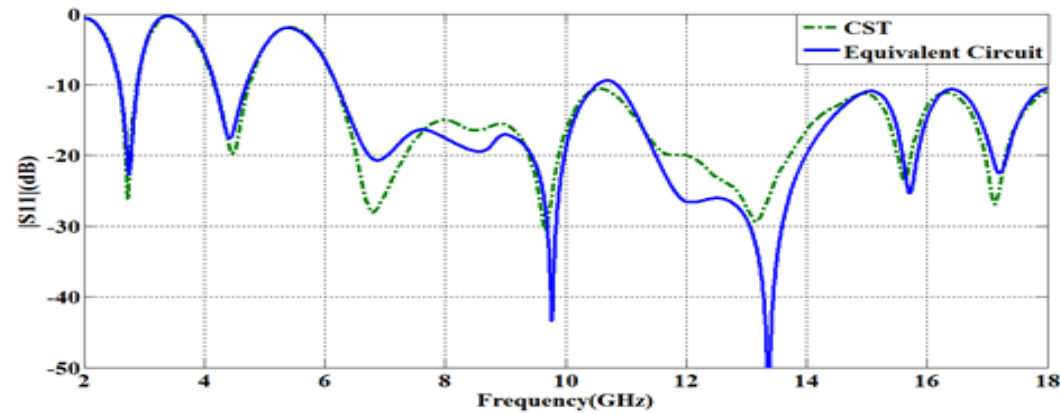

(a)

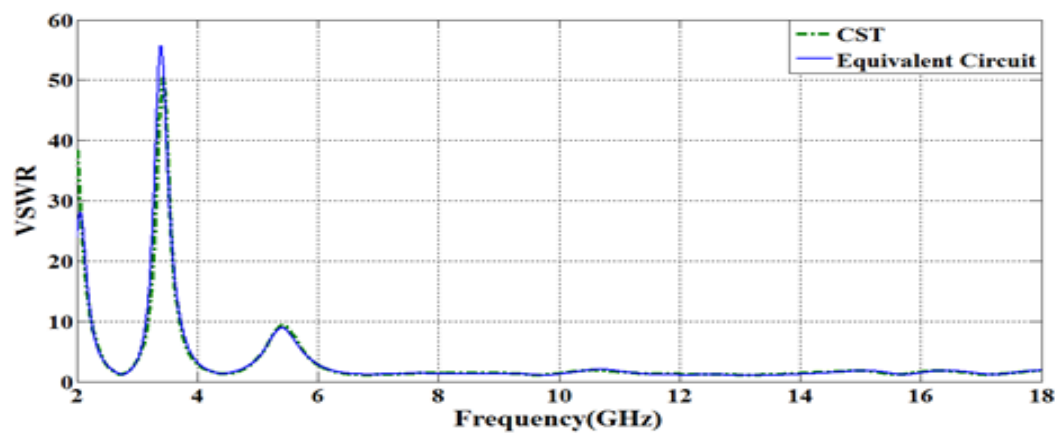

(b)

Fig. 13. Comparison of $\left(S_{11}\right)$ and VSWR of the proposed antenna that achieved using the CST and the SPICE circuit.

\section{Conclusions}

A semi-circular monopole antenna for double band-rejected UWB antenna operation has been proposed. Double band- rejected characteristics at $3.5 \mathrm{GHz}$ and $5.5 \mathrm{GHz}$ are attained by etching an arc slot in the patch and introducing a T-stub on the feeding line. Parametric analysis for the main effective parameters of the antenna has been performed to demonstrate the effect of these parameters and develop the best values of the antenna parameters. The simulation results indicated that the proposed antenna offers a very wide bandwidth from $2.7 \mathrm{GHz}$ to more than $18 \mathrm{GHz}$ with two rejected bands, covering the 5.5 GHz WLAN, 3.5GHz WiMAX. The stable radiation patterns and fairly constant gain indicate that the suggested antenna is well suited to be combined within portable devices used in various UWB applications. An equivalent circuit for the suggested monopole antenna is achieved using the Advanced Design System (ADS) and MATLAB. It was found a reasonable counterpart between the simulated results using CST- Microwave Studio and the results of the suggested equivalent circuit for the proposed antenna was shown.

\section{References}


[1] Azim, R. et al. : Design of a dual band-notch UWB slot antenna by means of simple parasitic slits. IEEE Antennas and Wireless Propagation Letters.Vol.12, PP.1412-1415 (2013).

[2] Sayidmarie, K. H., and Najm, T.A. : Performance evaluation of band-notch techniques for printed dualband monopole antennas. International Journal of Electromagnetics and Applications. Vol.3, No.4, PP. 70-80, (2013).

[3] Kang, X. et al. :A band-notched UWB printed half elliptical ring monopole antenna. Progress In Electromagnetics Research C. Vol. 35, PP. 23-33, (2013).

[4] Boroomandisorkhabi, B. et al. : A novel UWB circular CPW antenna with triple notch band characteristics. Loughborough Antennas \& Propagation Conference. PP.637-640, Loughborough, UK, 1112 November (2013).

[5] Kong, Y. et al. : A Triple band-notched UWB antenna using an arc-shaped slot and a U-shaped resonator techniques. Progress In Electromagnetics Research Symposium Proceedings. PP. 1588-1592, July (2015).

[6] Li, Y. et al. : A simple monopole slot antenna with high band-notch characteristics for ultra-wideband communication applications. Progress In Electromagnetics Research Symposium Proceedings. PP. 17511755, July (2015).

[7] Tomar, S., and Kumar, A. : Design of a triple band-notched UWB planar monopole antenna. Journal of Microwaves, Optoelectronics, and Electromagnetic Applications. Vol. 14, No. 2, PP.184-196, Dec. (2015).

[8] Ashokrao, P.S. et al.: Design of UWB microstrip antenna with band-notch for broadband application. International Journal of Engineering Research and Technology (IJERT). Vol. 4, Issue 05, PP.920-923, May (2015).

[9] Iqbal, A. et al. : A Compact UWB antenna with independently controllable notch bands. Sensors, 19, 1411; doi:10.3390/s19061411, 2019.

[10] Dong, J. et al.: Compact planar ultrawideband antennas with 3.5/5.2/5.8 GHz triple band-notched characteristics for Internet of things applications. www.mdpi.com/journal/sensors, 17, 349; doi:10.3390/s17020349, (2017).

[11] Ibrahim, A. et al.: UWB monopole antenna with band-notched characteristics mitigating interference with WiMAX. Radio Engineering, Vol. 26, No. 2, PP.438-443, June (2017).

[12] Sanyal, R. et al.: Miniaturized band-notched UWB antenna with improved fidelity factor and pattern stability. Radio Engineering. Vol. 27, No. 1, PP.39-46, April (2018).

[13] Jaglan, N. et al.: Design of band-notched antenna with DG-CEBG. International Journal of Electronics. Vol. 105, No.1, PP. 58-72 (2018).

[14] Siddique, A. K. M., et al. : Compact planar ultra-wideband antenna with dual notched band for WiMAX and WLAN. International Journal of Microwave and Wireless Technologies, Vol. 11, Special Issue 7, Sept. 2019, (Mikon 2018).

[15] Puri, S. C., et al. : UWB monopole antenna with dual-band-notched characteristics. Microwaves and Optical Technology Letters, Vol. 63, Issue 3 (2020).

[16] Chuicai Rong, C., et al. : A Double Band-Notched UWB Antenna for Flexible RF Electronics. Applied Computational Electromagnetics Society Journal, Vol. 32, No. 5, pp. 413-417 (2017).

[17] Sayidmarie, K. H., and Yahya, L. S.: Analysis, design, and modeling of crescent antenna for UWB applications. Sixth International Conference on Internet Technologies and Applications.8-11Sept. Wales, UK (2015).

[18] Kumar, G., and Ray, K. P. : Broadband microstrip antennas. Artech House.Boston, London (2003).

[19] Sayidmarie, K. H. and Yahya, L. S. : Modeling of dual-band Crescent- Shape monopole antenna for WLAN applications. International Journal of Electromagnetics and Applications. Vol. 4, No.2, PP. 31-39, (2014). 